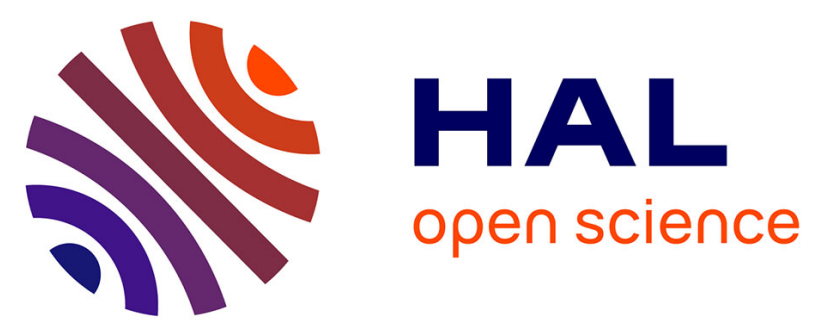

\title{
Phase behaviour and electro-optical response of systems composed of nematic liquid crystals and poly (2-ethylhexylacrylate)
}

\author{
Amina Bouriche, Lamia Bedjaoui Alachaher, Ulrich Maschke
}

\section{To cite this version:}

Amina Bouriche, Lamia Bedjaoui Alachaher, Ulrich Maschke. Phase behaviour and electro-optical response of systems composed of nematic liquid crystals and poly (2-ethylhexylacrylate). Liquid Crystals, 2017, Liquid Crystals, 45 (5), pp.656-665. 10.1080/02678292.2017.1370562 . hal-02379508

\section{HAL Id: hal-02379508 \\ https://hal.univ-lille.fr/hal-02379508}

Submitted on 8 Jan 2021

HAL is a multi-disciplinary open access archive for the deposit and dissemination of scientific research documents, whether they are published or not. The documents may come from teaching and research institutions in France or abroad, or from public or private research centers.
L'archive ouverte pluridisciplinaire HAL, est destinée au dépôt et à la diffusion de documents scientifiques de niveau recherche, publiés ou non, émanant des établissements d'enseignement et de recherche français ou étrangers, des laboratoires publics ou privés. 


\section{Phase behaviour and electro-optical response of systems composed of nematic liquid crystals and poly (2-ethylhexylacrylate)}

Running title: Properties of LC/poly(2-ethylhexylacrylate) systems

Amina Bouriche ${ }^{\mathrm{a}, \mathrm{b}}$, Lamia Bedjaoui Alachaher ${ }^{\mathrm{b}}$, and Ulrich Maschke*,a

${ }^{\mathrm{b}}$ Laboratoire de Recherche sur les Macromolécules (LRM), Faculté des Sciences, Université Aboubakr Belkaïd de Tlemcen, 13000 Tlemcen, Algeria.

Fax : 0033320436591 ; e-mail : ulrich.maschke@univ-lille1.fr 


\section{Abstract}

Experimental studies of phase diagram and morphology of mixtures composed of linear poly(2-ethylhexylacrylate) (poly-2EHA) of molecular weight $\mathrm{M}_{\mathrm{w}}=92000 \mathrm{~g} / \mathrm{mol}$ and $\mathrm{E} 7$, an eutectic blend of nematic liquid crystals (LCs), were performed. The latter consists of four cyanoparaphenylenes i.e. 4-cyano-4'-n-pentyl-biphenyl (5CB), 4-cyano-4'-n-heptyl- biphenyl (7CB), 4-cyano-4'-n-oxyoctyl-biphenyl (8OCB), and 4-cyano-4'”-n-pentyl-p-biphenyl (5CT). Thermal properties of the poly-2EHA/E7 system were studied by differential scanning calorimetry and the sample morphologies were investigated by optical microscopy. Phase diagram analysis revealed an increase of the nematic-isotropic transition temperature when E7 was added to poly-2EHA, compared to pure E7. This effect, related to a preferential miscibility phenomenon of E7 components towards poly-2EHA, was evidenced by gas chromatography analysis coupled to mass spectrometry (GC-MS), allowing to qualify and quantify the content of phase separated LC domains.

Thermograms of model LC mixtures including 5CB, 7CB, 8OCB and 5CT, which correspond to their composition in segregated LC domains of poly-2EHA/E7, present strong deviations from eutectic behavior. In order to access the impact of such variations for practical applications, such a model LC mixture was introduced in photochemically crosslinked 2-EHA (polycross-2EHA). Surprisingly, the electro-optical response of the obtained polycross2EHA/LC films was considerably improved compared to the original polycross-2EHA/E7 system.

Keywords: eutectic liquid crystal; poly(2-ethylhexylacrylate); phase behavior; morphology; photopolymerization; electro-optical response. 


\section{Introduction:}

Polymer Dispersed Liquid Crystal (PDLC) film consists generally of micron-sized nematic liquid crystalline (LC) domain dispersed in a polymer matrix [1-5]. They have been subject of intensive studies [6-8], because of both fundamental interest and potential applications in the field of smart windows, optical shutters, active display devices, sensors, microlenses and smart food packaging. Their unique electro-optical properties make them suitable for a large range of opto-electronical to biomedical devices [9-18]. In the field off-state, the PDLC film scatters light due to mismatch between the effective refractive index ( $\left.\mathrm{n}_{\mathrm{eff}}\right)$ of the LC and that of the polymer $\left(n_{p}\right)$. In the field on-state, LCs of positive anisotropy tend to align with their nematic director parallel to the field direction. In such a state, refractive index matching occurs and the PDLC film becomes transparent.

Generally, PDLC materials can be obtained by different methods [19]: thermally induced phase separation (TIPS), solvent evaporation induced phase separation (SIPS), polymerization/crosslinking induced phase separation (PIPS) and emulsion or encapsulation [20]. The choice of one of these methods can lead to specific features of PDLC films [21]. In many applications, commercial multicomponent LC mixtures like the well-known eutectic nematic E7 are used, since they possess high anisotropy over a large temperature range. As an example, E7 exhibits a single nematic to isotropic transition temperature at $\mathrm{T}_{\mathrm{NI}}=61^{\circ} \mathrm{C}$ and a glass transition temperature at $\mathrm{T}_{\mathrm{g}}=-62^{\circ} \mathrm{C}$, providing a large nematic range of approximately $120^{\circ} \mathrm{C}$. In most cases these transition temperatures seems to remain identical in the presence of a polymer, however some authors report about exceptions which were explained by preferential solubility effects of the constituents of these eutectic LC blends towards the polymer. A short overview of the literature shows that this phenomenon was obtained with several polymer/LC systems like UV curable resin NOA65/E7 [22] and NOA65/E44 [23], for which the phase behavior of the LC-rich domains deviate remarkably from those of pure 
eutectic LC mixtures. For the first system [22], gas chromatographic (GC) analysis showed an important deviation compared to the original composition of E7. In the second system NOA65/E44, the heterogeneity of LC domains formed after photopolymerization, compared with results involving a pure LC (7CB), was attributed to different miscibilities of the E44 compounds towards NOA65.

Other systems were concerned by large shifts of phase transition temperatures in polymer/LC films; for example thermo-optical studies of poly(methylmethacrylate)/E7 [24] showed an increase of $\mathrm{T}_{\mathrm{NI}}$, indicating preferential solubility during the phase-separation process. The same effect was observed on poly(methylphenylsiloxane) (PMPS)/E7 phase diagrams [25,26], by varying the molecular weight of the polymer. It has been noticed in the case of the molecular weight of $60000 \mathrm{~g} / \mathrm{mol}$ that the nematic-isotropic transition temperature increased by nearly $20^{\circ} \mathrm{C}$ when adding 80 weight $\%$ of polymer to E7. In a study of the phase behavior and morphology of poly(n-butylacrylate) (polyABu)/E7 blends, High Performance Liquid Chromatography (HPLC) analysis of the separated LC domains revealed relatively high solubility of 5CB with polyAbu, compared with PMPS [27,28].

In the present work, the range of investigated polymeric systems was extended to poly (2ethylhexylacrylate) (poly-2EHA), and analysis of the preferential solubility phenomenon was conducted by several techniques, such as Polarizing Optical Microscopy (POM) and Differential Scanning Calorimetry (DSC). In addition, GC coupled with Mass Spectrometry (GC-MS) was employed as promising method for the determination of the content of segregated LC domains from the poly-2EHA/E7 system.

To the best of our knowledge, no data are currently available in literature describing the consequences of the phenomenon of preferential solubility on electro-optical properties of corresponding PDLC films. Generally, electro-optical characteristics of PDLC films were examined by varying various parameters such as nature, architecture and concentration of LC 
and polymer, film thickness, and morphology [29], [30]. In this report the electro-optical performance of photochemically crosslinked poly-2EHA (polycross-2EHA)/LC films will be analyzed, using model LC blends prepared according to the compositional results obtained from GC-MS results.

\section{Experimental}

\subsection{Materials}

The monofunctional monomer 2-Ethyl Hexyl Acrylate (2EHA) (Figure 1a) was obtained from Sigma-Aldrich, the difunctional isotropic crosslinking agent hexanedioldiacrylate (HDDA) (Figure 1b) was supplied by Cray Valley and the photo-initiator 2-hydroxy-2-methyl-1phenyl-1-propanone (Darocur 1173) was obtained from Ciba-Geigy. The poly (2-Ethyl Hexyl Acrylate) (poly-2EHA) had an average molecular weight $\mathrm{M}_{\mathrm{w}}=92.000 \mathrm{~g} / \mathrm{mol}$ and was supplied from Sigma Aldrich. The polydispersity of this polymer was determined by gel permeation chromatography (GPC) performed in tetrahydrofuran (THF) at room temperature yielding $\mathrm{M}_{\mathrm{w}} / \mathrm{M}_{\mathrm{n}}=3$. E7 represents a commercially available eutectic LC mixture and was purchased from Synthon GmbH, Germany. It contains 51wt.-\% of 4-cyano-4'-n-pentyl-biphenyl (5CB), 25wt.-\% of 4-cyano-4'-n-heptyl-biphenyl (7CB), 16wt.-\% of 4-cyano-4'-n-oxyoctyl-biphenyl (8OCB) and 8wt.-\% of 4-cyano-4"'-n-pentyl-p-biphenyl (5CT) [31]. E7 exhibits a single $\mathrm{T}_{\mathrm{NI}}$ at $61{ }^{\circ} \mathrm{C}$ and a glass transition temperature $\mathrm{T}_{\mathrm{g}}$ at $-62^{\circ} \mathrm{C}$. The refractive indices of $\mathrm{E} 7$ at $\mathrm{T}=$ $20^{\circ} \mathrm{C}$ are given as $\mathrm{n}_{\mathrm{o}}=1.5183 ; \mathrm{n}_{\mathrm{e}}=1.7378(\lambda=632.8 \mathrm{~nm})$, leading to a birefringence of $\Delta \mathrm{n}=\mathrm{n}_{\mathrm{e}^{-}}$ $\mathrm{n}_{\mathrm{o}}=0.2195$ [32]. The details of the chemical structures of LC molecules involved in E7 were presented in Figure 1c. The LC 4-cyano-4'-n-butyl-biphenyl (4CB) supplied by Merck was used as a standard to establish the calibration curves needed for GC-MS analysis; its chemical structure is illustrated in Figure 1d. 
(a)<smiles>C=CC(=O)OCC(CC)CCCC</smiles>

$51 \%$ wt $(5 \mathrm{CB})$

$25 \%$ wt $(7 \mathrm{CB})$

$16 \%$ wt $(8 \mathrm{OCB})$ (b)<smiles>C=CC(=O)OCCCCCCOC(=O)C=C</smiles>

(c)
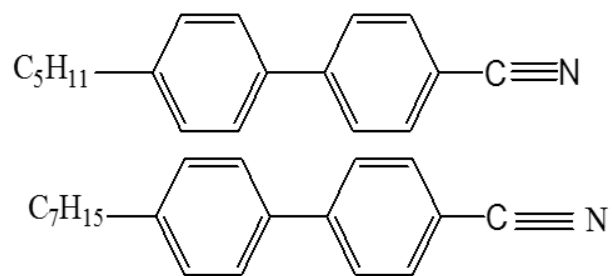

$8 \%$ wt $(5 \mathrm{CT})$

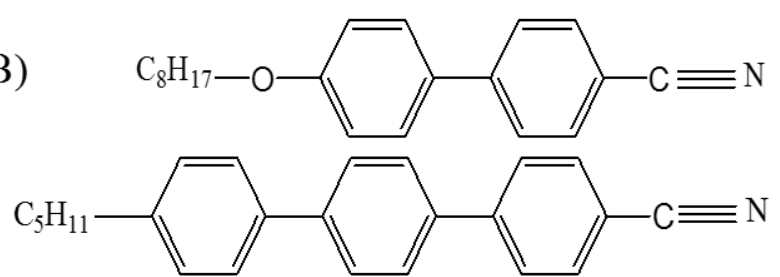

c)

(d)

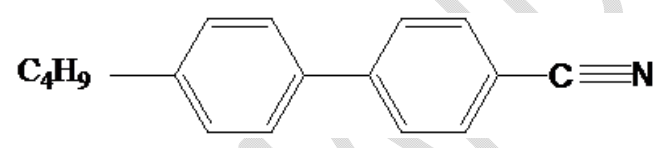

Figure 1) Chemical structures of (a) 2-Ethylhexylacrylate (2EHA) monomer, (b) Hexanedioldiacrylate (HDDA), (c) nematic LC E7, and (d) 4-cyano-4'-n-butyl-biphenyl (4CB).

\subsection{Sample preparation}

The poly-2EHA/E7 blends were prepared by the TIPS process. $\mathrm{x}$ wt.- $\%$ of E7 $(\mathrm{x}=10 ; 20 ; \ldots$; $90)$ and $(100-x)$ wt.- $\%$ of poly-2EHA were mixed together at room temperature for several hours. The phase behavior of poly-2EHA/E7 mixtures was already established experimentally by POM [33-34] and will thus be analyzed by DSC. To investigate the electro-optical performance of polymer/LC systems, PDLC films were prepared by the PIPS technique. Blends of (2EHA/HDDA/Darocur 1173) (96/2/2wt.-\%) together with a LC mixture, either E7 or a model blend, were polymerized/crosslinked under UV-visible irradiation for $30 \mathrm{~min}$. The 
LC concentration of the precursor blends was kept at $70 \mathrm{wt} .-\%$ to achieve a homogeneous thermodynamic state. The photopolymerization/crosslinking process was carried out by irradiating the sample cells under a Philips TL08 UV light source, possessing a maximum output at a wavelength of $\lambda=365 \mathrm{~nm}$, and a dose rate of $0.5 \mathrm{~mJ} / \mathrm{cm}^{2}$. The cells were assembled using two $1 \mathrm{~mm}$ thick plane parallel glass plates, which were coated inside with thin transparent conductive layers of indium tin oxide (ITO). The size of the cells was $1 \mathrm{cmx} 1 \mathrm{~cm}$.

\subsubsection{Polarized optical microscopy}

For polarized optical microscopy (POM) experiments, an Olympus BX41 apparatus, equipped with a Linkam heating/cooling stage LTS350 together with a temperature-controlling unit TMS 94, was used. The samples were placed between two micro glass slides, then heated up until they became optically clear, and then cooled down slowly to ambient temperature. The heating and cooling rates were $0.5^{\circ} \mathrm{C} / \mathrm{min}$. The same heating/cooling procedures were repeated three times for each sample to minimize experimental uncertainties.

\subsubsection{Thermal characterization}

Thermal properties like determination of phase transition temperatures and enthalpies of polymer/LC blends were investigated by DSC (Perkin-Elmer model 8000). Samples were prepared by introducing about $8-10 \mathrm{mg}$ of the initial mixture into aluminum DSC pans, to avoid evaporation effects during the temperature treatment. A rate of $10^{\circ} \mathrm{C} / \mathrm{min}$ (heatingcooling cycle) was used in the temperature range from $72^{\circ} \mathrm{C}$ to $+100^{\circ} \mathrm{C}$. The program consisted first in cooling the sample, followed by three heating and cooling cycles to take into account eventual thermal events related to the sample preparation history. A Pyris computer software from Perkin-Elmer was used to determine the onset temperature of the various phase transitions. Only thermograms from the second heating scan were considered for the analysis. 
The DSC apparatus was calibrated using indium and zinc as standards at a heating rate of $10^{\circ} \mathrm{C} / \mathrm{min}$.

\subsubsection{GC-MS analysis}

GC-MS analysis was carried out on a Perkin Elmer Turbo Mass Spectrophotometer (Norwalk, USA) which includes a Perkin Elmer Auto sampler XLGC. The column used was a Perkin Elmer Elite-5 capillary column measuring $30 \mathrm{~m} \times 0.25 \mathrm{~mm}$ with a film thickness of $0.25 \mathrm{~mm}$ composed of 95\% Dimethylpolysiloxane. The carrier gas used was Helium at a flow rate of $2.5 \mathrm{~mL} / \mathrm{min}$. Injection volumes of $0.4 \mu \mathrm{L}$ were used per sample. The oven temperature program was as follows: temperature was kept at $100^{\circ} \mathrm{C}$ for $15 \mathrm{~min}$ and then increased to $150^{\circ} \mathrm{C}$ with a rate of $10^{\circ} \mathrm{C} / \mathrm{min}$ followed by an isotherm period of $10 \mathrm{~min}$.; then temperature was increased to $240^{\circ} \mathrm{C}\left(10^{\circ} \mathrm{C} / \mathrm{min}\right)$ followed by another isothermal period of $10 \mathrm{~min}$. Injection port and transfer line temperatures were set at $300^{\circ} \mathrm{C}$ and $180^{\circ} \mathrm{C}$, respectively. GC-MS analysis was carried out using electron impact ionization at $70 \mathrm{eV}$ and data were evaluated using total ion count (TIC) for compound identification and quantification. The spectra of the components were compared with known components stored in the GC-MS database. Measurement of peak areas and data processing were carried out by Turbo Mass-OCPTVS-Demo SPL software. To establish the calibration curves, the internal calibration method was chosen by adding 4CB as standard. This standard was added to the LC sample to be analyzed with a constant concentration of $1 \mathrm{mg} / \mathrm{mL}$.

\subsubsection{Electro-optical measurements}

For electro-optical measurements, the collimated beam from a $\mathrm{He} / \mathrm{Ne}$ laser $(\lambda=632.8 \mathrm{~nm})$ passed through the sample cell at an angle of $90^{\circ}$ compared to the cell surface, and the transmitted light was collected by a photodiode. Using a standard frequency and function 
generator together with a voltage amplifier, an electric field was applied across the samples (1kHz-sinusoidal). Optical transmission curves were thus obtained as function of the applied voltage, allowing to extract characteristic parameters such as $\mathrm{V}_{10}$, representing the voltage corresponding to $10 \%$ of transmitted light. $\mathrm{T}_{\mathrm{OFF}}$ and $\mathrm{T}_{\mathrm{ON}}$ correspond to the light transmitted in the OFF and ON states, respectively.

\section{Results and discussion}

Thermograms of the poly-2EHA/E7 system obtained from DSC measurements are displayed in Figure 2.

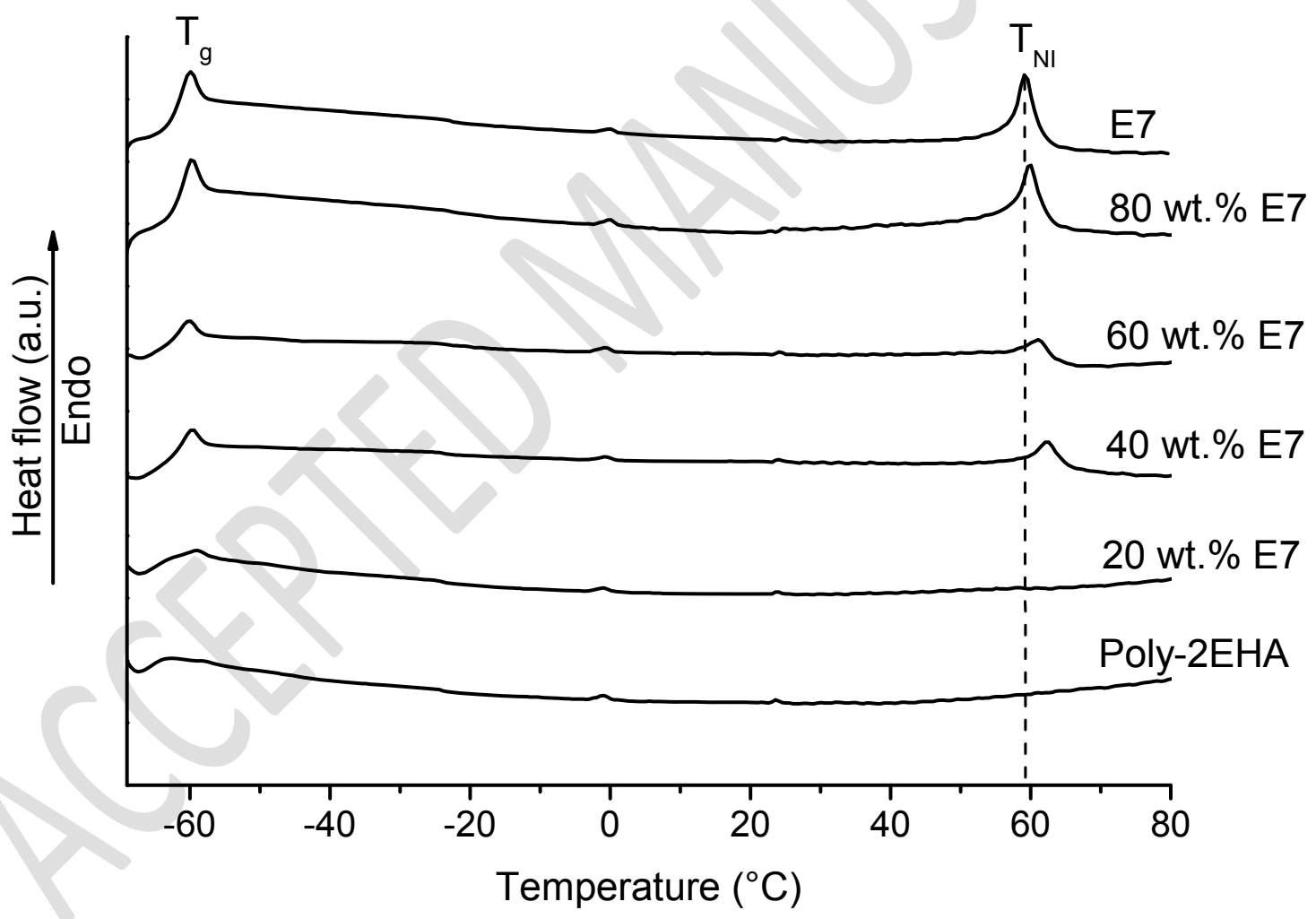

Figure 2) Thermograms obtained from DSC measurements (heating rate $10^{\circ} \mathrm{C} / \mathrm{min}$ ) for a series of poly-2EHA/E7 mixtures for LC concentrations ranging from 0 to $100 \mathrm{wt} .-\%$. $\mathrm{T}_{\mathrm{g}}$ represents the glass transition temperature and $\mathrm{T}_{\mathrm{NI}}$ stands for the nematic to isotropic transition temperature. 
The poly-2EHA/E7 blends were analyzed using increments of 10wt.- $\%$ starting from pure poly-2EHA to pure E7. In Figure 2, the heat flow of each poly-2EHA/E7 mixture was represented as function of temperature, covering a wide range from $-72^{\circ} \mathrm{C}$ up to $+100^{\circ} \mathrm{C}$, which allows detection of various transition temperatures, such as $\mathrm{T}_{\mathrm{NI}}$ of the $\mathrm{LC}$ and $\mathrm{T}_{\mathrm{g}}$ of the polymer and LC. The pure LC E7 is characterized by two transition temperatures: a glass transition at low temperature $\left(\mathrm{T}_{\mathrm{g}}=-62^{\circ} \mathrm{C}\right)$ and a nematic-isotropic transition at higher temperature $\left(\mathrm{T}_{\mathrm{NI}}=+61^{\circ} \mathrm{C}\right)$. No other transition occurs, and the nematic phase covers a wide range of temperatures. Above $\mathrm{T}_{\mathrm{NI}}$, $\mathrm{E} 7$ adopts an isotropic phase. The glass transition temperature of poly-2EHA was about $T_{g}=-63^{\circ} \mathrm{C}$ and was almost coincident with $T_{g}$ of E7. By increasing the poly-2EHA concentration starting from pure E7, the nematic-isotropic transition shifts to higher temperatures, while the exothermic peak widens slightly.

The superposition of the variation of the nematic-isotropic transition temperatures, depending on the sample composition, is presented in Figure 3a. These data were obtained by POM and DSC. Results from DSC correspond to the peak maxima of the thermograms and those obtained by POM represent onset (beginning) and end of the transition. An increase of the nematic-isotropic transition temperatures was observed with decreasing LC amount in the poly-2EHA/E7 mixture. These results show a good correlation between the two characterization methods. This increase can be explained by a preferential solubility phenomenon between the different components of E7 and poly-2EHA.

Investigations were carried out earlier on different systems such as PMPS/E7 [25] and $\mathrm{PABu} / \mathrm{E} 7$ [35], to analyse the phenomenon of preferential solubility between the polymer and the LC. In Figure 3b, an attempt was made to correlate the results of all these systems in terms of the temperature ratio $\mathrm{T}_{\mathrm{NI}-\mathrm{m}} / \mathrm{T}_{\mathrm{NI}-\mathrm{p}}$, as a function of the polymer composition. 


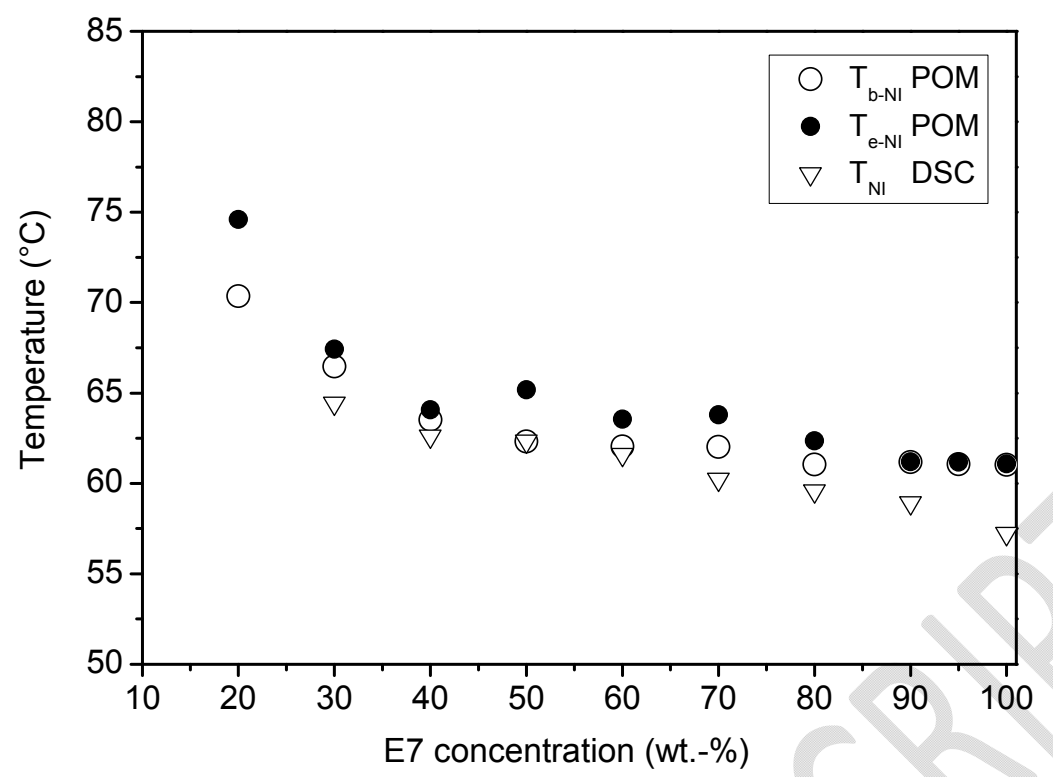

(a)

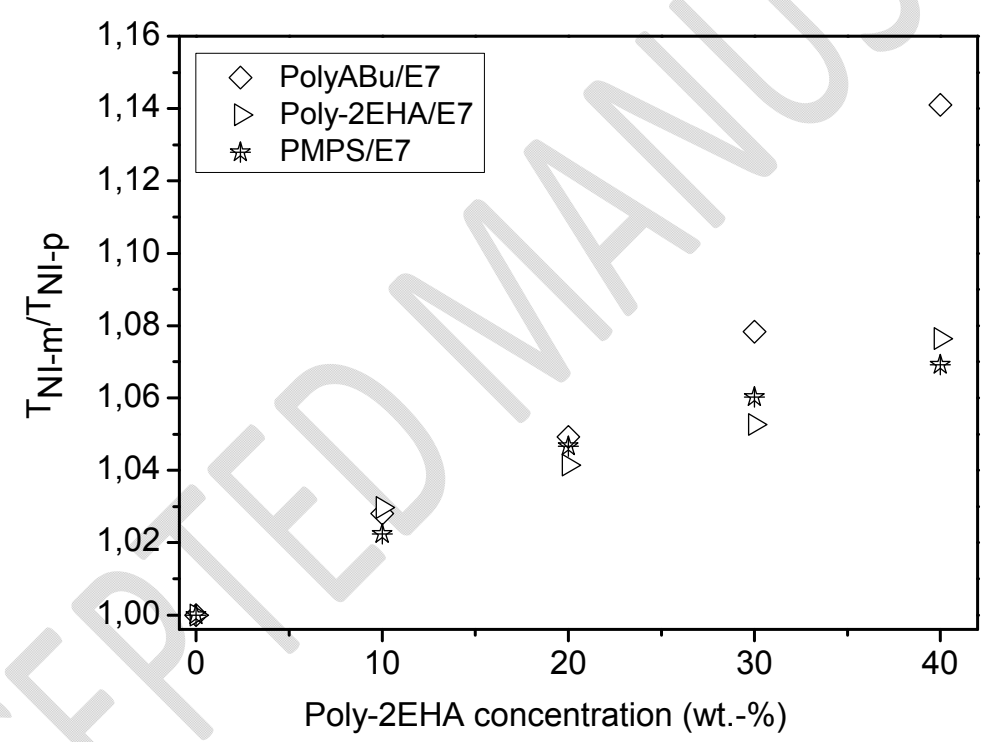

(b)

Figure 3) (a) Superposition of $\mathrm{T}_{\mathrm{NI}}$ data obtained by POM and DSC of the poly-2EHA/E7 system. $\mathrm{T}_{\mathrm{b}-\mathrm{NI}}$ and $\mathrm{T}_{\mathrm{e}-\mathrm{NI}}$ correspond to beginning and end of appearance of the $\mathrm{T}_{\mathrm{NI}}$ transition observed by POM, respectively. (b) Variation of $\mathrm{T}_{\mathrm{NI}-\mathrm{m}} / \mathrm{T}_{\mathrm{NI}-\mathrm{p}}$ of polymer/E7 systems versus polymer concentration obtained from POM. $\mathrm{T}_{\mathrm{NI}-\mathrm{m}}$ corresponds to the nematic-isotropic transition temperatures of LC of polymer/E7 mixtures (PMPS/E7 [25], PABu/E7 [35]). $\mathrm{T}_{\mathrm{NI}-\mathrm{p}}$ represents $\mathrm{T}_{\mathrm{NI}}$ of pure LC E7. 
This ratio was calculated by taking into account the nematic-isotropic transition temperatures $\mathrm{T}_{\mathrm{NI}-\mathrm{m}}$, corresponding to the LC part of polymer/E7 mixtures, and $\mathrm{T}_{\mathrm{NI}-\mathrm{p}}$, representing the nematic-isotropic transition temperature of pure LC E7. In all cases considered here, these transition temperatures show an increase with the polymer concentration. Results from PMPS/E7 and poly-EHA/E7 were found to be similar, whereas the PABu/E7 system presents a more pronounced effect on $\mathrm{T}_{\mathrm{NI}}$.

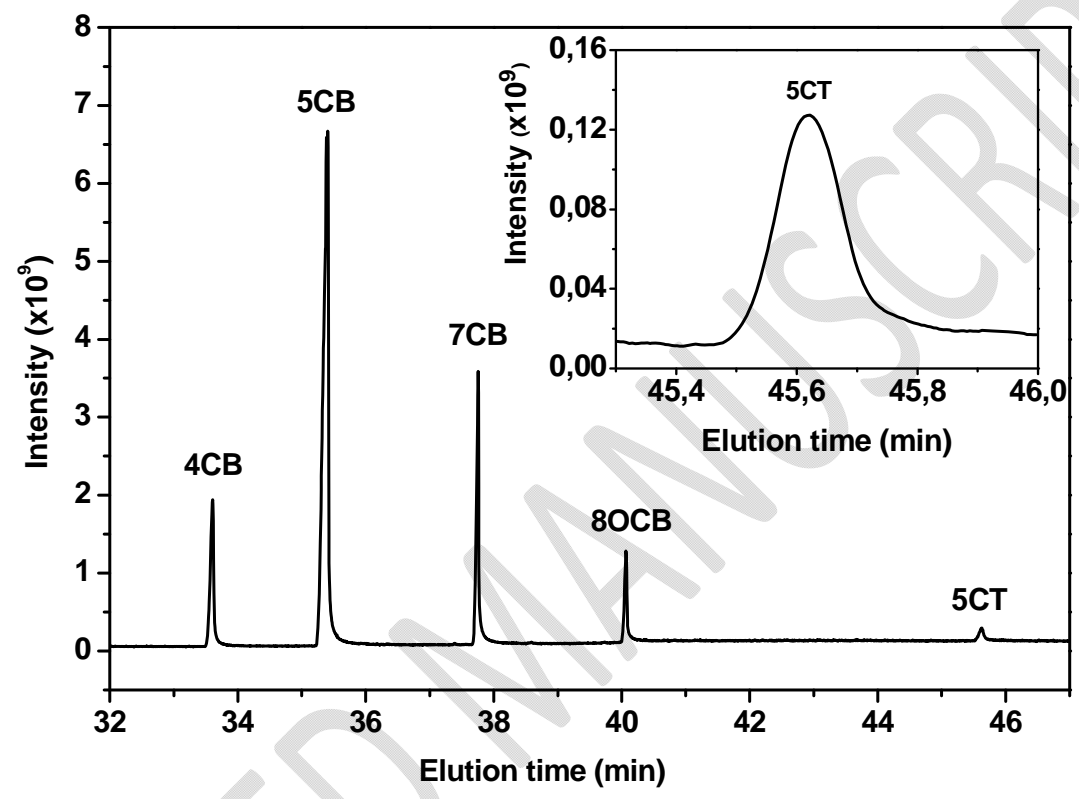

(a)

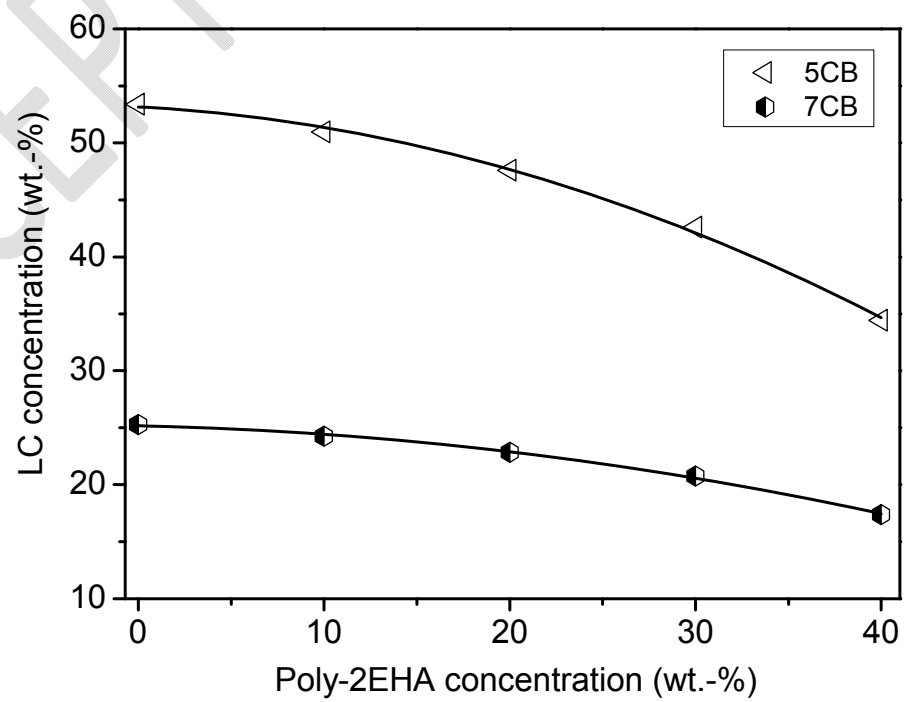

(b) 


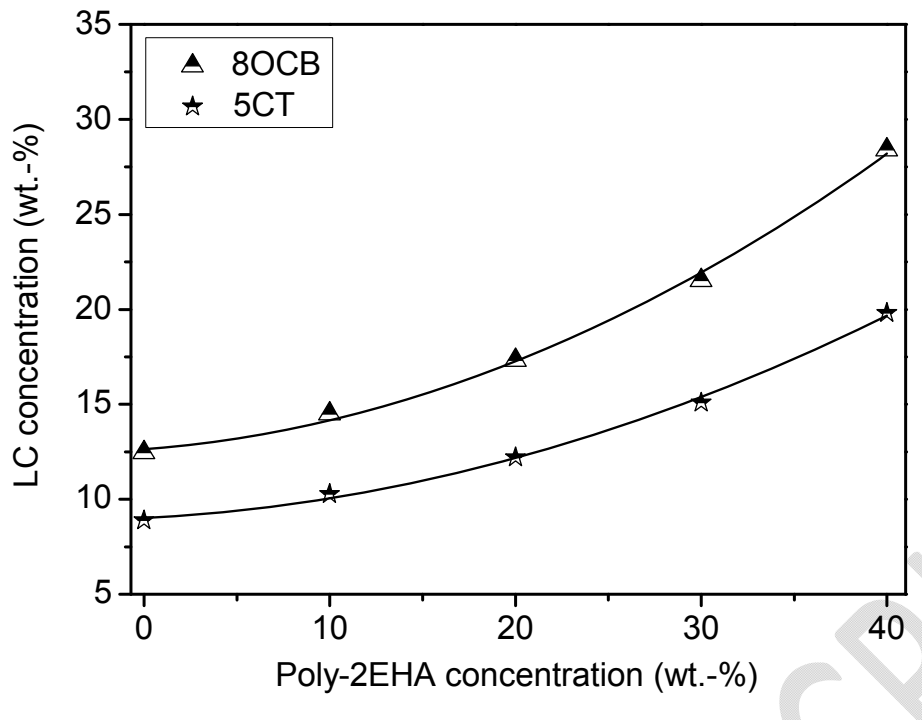

(c)

Figure 4) (a) Chromatogram of LC E7 obtained by GC, (b) and (c): Variation of the concentration of $\mathrm{E} 7$ components $(5 \mathrm{CB}, 7 \mathrm{CB}, 8 \mathrm{OCB}$ and $5 \mathrm{CT})$ depending on poly-2EHA content of the initial poly-2EHA/E7 mixtures, obtained from GC-MS data.

The combination between GC and MS represents a powerful method to identify and quantify LC compounds included in LC mixtures like E7. Calibration curves were established for each component relative to an added internal standard which was $4 \mathrm{CB}$. Figure 4a shows the result of the separation of pure E7 by GC-MS, and Figures $4 \mathrm{~b}$ and $4 \mathrm{c}$ display the outcome of the analysis of phase separated LC domains in poly-2EHA/E7 mixtures in terms of the variation of the concentrations of $5 \mathrm{CB}, 7 \mathrm{CB}, 8 \mathrm{OCB}$, and $5 \mathrm{CT}$. The $\mathrm{x}$-axis of Figure $4 \mathrm{~b}$ and $4 \mathrm{c}$ correspond to the poly-2EHA concentration of the examined poly-2EHA/E7 blends. Similar results as for PMPS/E7 and $\mathrm{PABu} / \mathrm{E} 7$ were found, i.e. $5 \mathrm{CB}$ and $7 \mathrm{CB}$ concentrations decrease with increasing poly-2EHA concentration, whereas $8 \mathrm{OCB}$ and $5 \mathrm{CT}$ display opposite behavior. The dependences presented in Figures $4 \mathrm{~b}$ and $4 \mathrm{c}$ show that $5 \mathrm{CB}$ and $7 \mathrm{CB}$ are miscible to some extent with poly-2EHA while $8 \mathrm{OCB}$ and $5 \mathrm{CT}$ show poor affinity with the polymer. The variation of the $5 \mathrm{CT}$ concentration reveals to be quite important, and can lead to 
a strong increase of $\mathrm{T}_{\mathrm{NI}}$ of the segregated LC domains due to its high nematic-isotropic transition temperature which corresponds to $240^{\circ} \mathrm{C}$. The results are consistent with the hypothesis proposed that the LC composition from separate domains varies depending on the polymer concentration, due to preferential miscibility phenomenon. It can be concluded that GC-MS data were helpful to qualify and quantify this effect observed by POM and DSC.

To confirm the obtained GC-MS results, DSC measurements were performed on samples made from four individual LC mixtures that correspond to the composition of the single LC compounds from segregated domains of poly-2EHA/E7 blends, which contain 10-40 wt.-\% poly-2EHA. The concentration data of these LC mixtures are reported in Table 1, and these LC-compositions were analyzed by DSC and POM.

\begin{tabular}{|c|c|c|c|c|}
\hline LC & 5CB (wt.- \%) & 7CB (wt.- \%) & 8OCB (wt.-\%) & 5CT (wt.-\%) \\
\hline E7 & 51 & 25 & 16 & 8 \\
\hline E7 (1) & 50,9 & 24,3 & 14,5 & 10,3 \\
\hline E7 (2) & 47,6 & 22,8 & 17,3 & 12,3 \\
\hline E7 (3) & 42,6 & 20,8 & 21,5 & 15,1 \\
\hline E7 (4) & 34,4 & 17,4 & 28,4 & 19,8 \\
\hline
\end{tabular}

Table 1: Composition of individual LC mixtures denoted E7 (1), E7 (2), E7 (3), and E7 (4), corresponding to the results from GC-MS measurements of segregated domains of the poly2EHA/E7 system.

Figure 5 gathers the thermograms of these four LC mixtures, showing a single glass transition and a single nematic-isotropic transition together with a large nematic region for E7 (1) and E7 (2). On the other hand, E7 (3) and E7 (4) present additional transitions at temperatures 
below room temperature, related to crystallization and melting effects, meaning that these mixtures cannot be furthermore considered as eutectic blends. These results clearly confirm the presence of a preferential miscibility effect of the poly-2EHA/E7 system and show an important impact for practical applications.

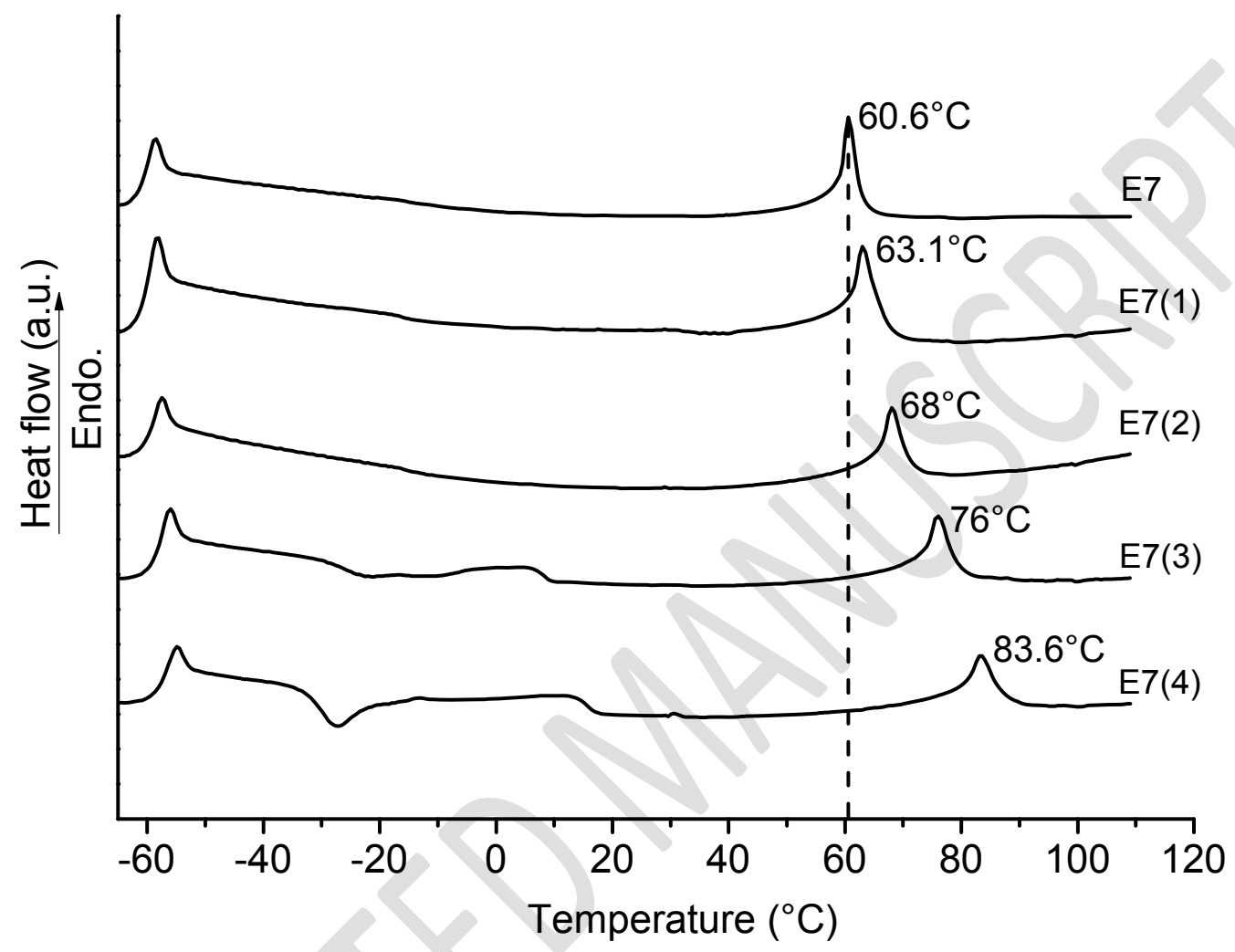

Figure 5) DSC thermograms of model LC mixtures composed of 5CB, 7CB, 8OCB and 5CT, which correspond to the compositions of the LCs from the segregated domains of the poly2EHA/E7 system, obtained from GC-MS investigations. The temperatures given on the thermograms correspond to the peak maxima of the $\mathrm{T}_{\mathrm{NI}}$ transition.

The results obtained from DSC thermograms were confirmed by POM observations. Figures $6 \mathrm{a}$ and $6 \mathrm{~b}$ represent typical nematic $\mathrm{LC}$ morphologies at $\mathrm{T}=25^{\circ} \mathrm{C}$ for pure $\mathrm{E} 7$ and model $\mathrm{LC}$ mixture E7 (4), respectively, showing both Schlieren textures exhibiting some differences in size and number of micro-domains. This change in morphology was particularly observed at 
the beginning of the nematic-isotropic phase transition showing that the micro-domains of E7

(4) possess larger sizes compared to those of the commercial E7. The texture of E7 (4) remains in the nematic state at $\mathrm{T}=70^{\circ} \mathrm{C}$ (Figure $6(\mathrm{~d})$ ), while that of pure E7 presents an isotropic phase at the same temperature (Figure $6(\mathrm{c})$ ).
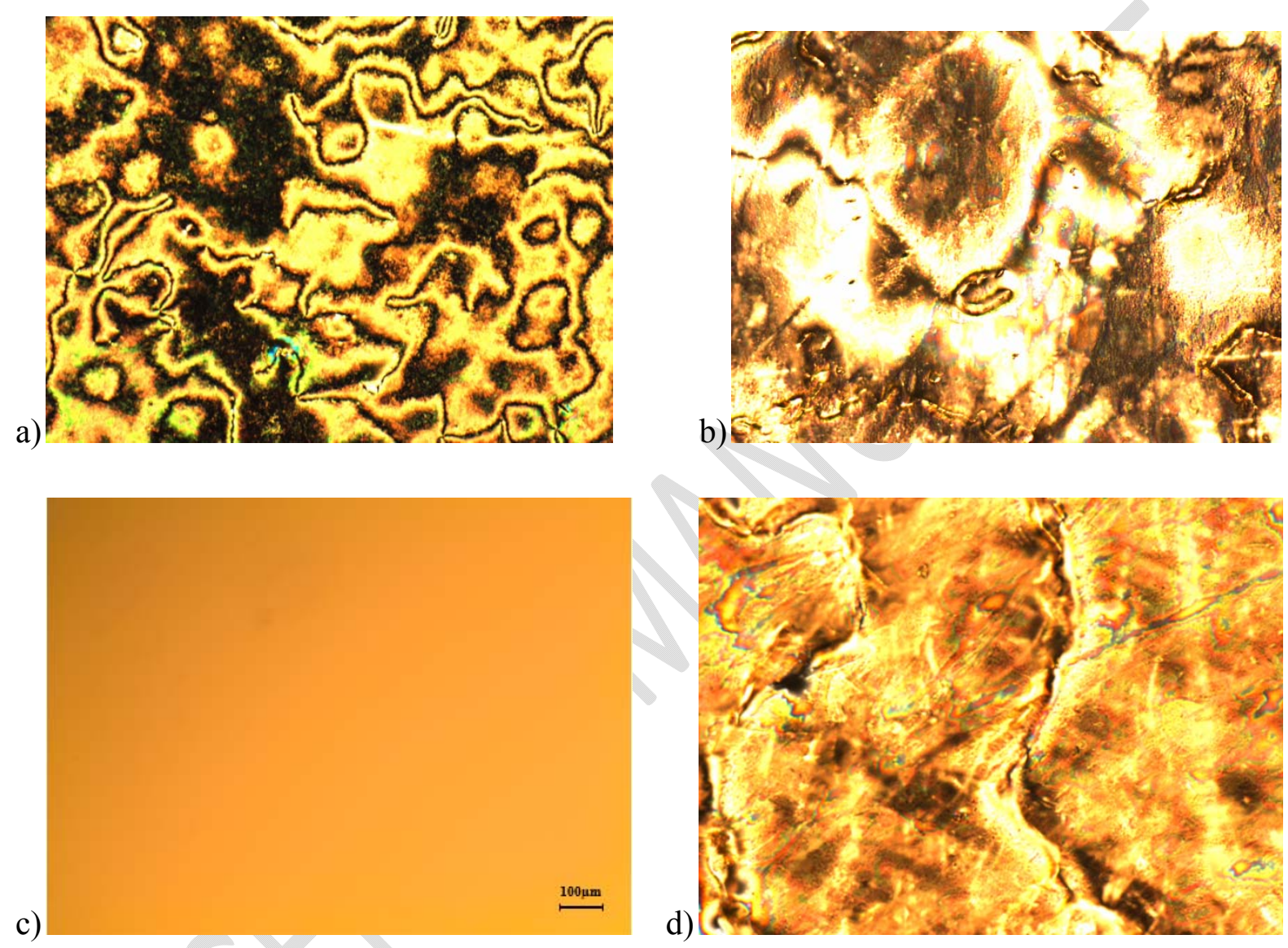

Figure 6) (a) and (c): POM pictures of LC E7 taken at $\mathrm{T}=25^{\circ} \mathrm{C}$ and $\mathrm{T}=70^{\circ} \mathrm{C}$, respectively; (b) and (d): Images from POM of model LC mixture E7 (4) obtained at $\mathrm{T}=25^{\circ} \mathrm{C}$ and $\mathrm{T}=70^{\circ} \mathrm{C}$, respectively. All observations were made during the heating cycle using the same magnification (representative scale bar for all images displayed on Figure 6 (c)).

An electro-optical investigation was undertaken to compare the electro-optical performance of poly-EHA systems including the commercial LC E7 with a LC composition that underwent a preferential miscibility phenomenon. The choice was focused on E7 (4) since this mixture 
should yield the most important effect on the electro-optical properties compared with the other model LC blends. DSC as well as POM results revealed a nematic-isotropic transition temperature around $83^{\circ} \mathrm{C}$ for this mixture together with a nematic phase present at room temperature necessary to be able to perform electro-optical studies.

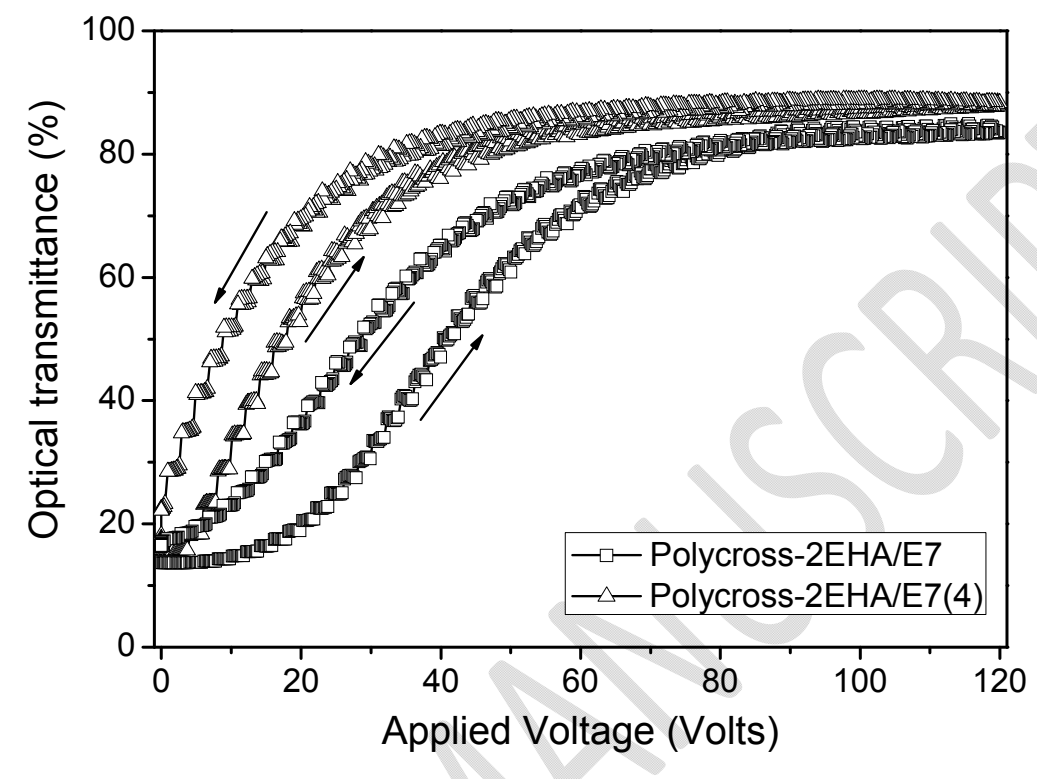

(a)

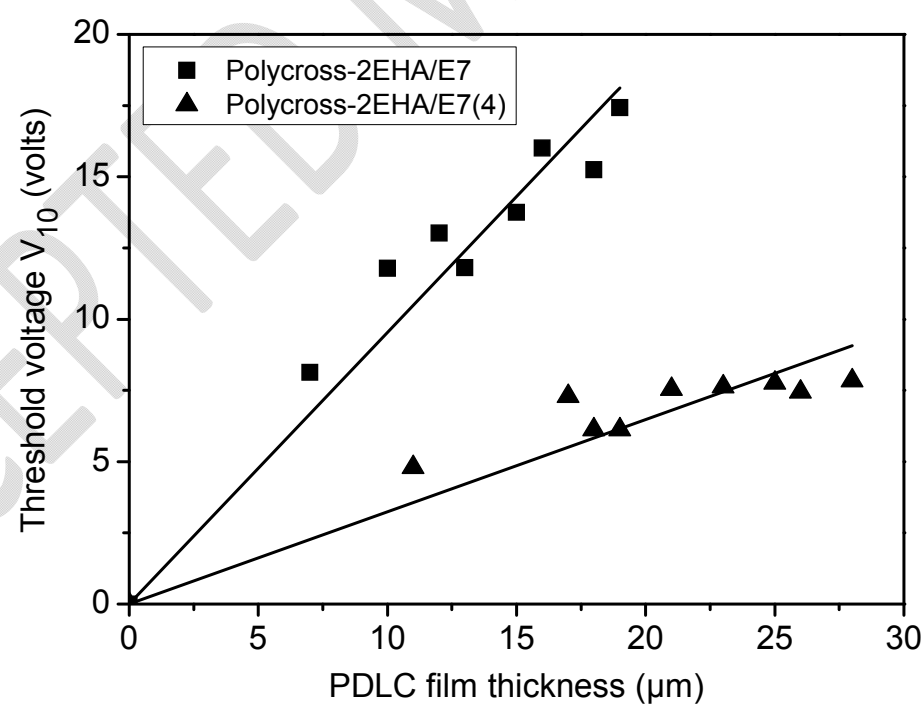

(b)

Figure 7) (a) Electro-optical responses of $19 \mu \mathrm{m}$ thick 30wt.-\% Poly (EHA/HDDA)/70wt.-\% E7 (pure) and 30wt.-\% Poly (EHA/HDDA)/70wt.-\% E7 (4) PDLC films, (b) Influence of the PDLC film thickness on threshold voltage $\left(\mathrm{V}_{10}\right)$. 
Figure 7a shows the superposition of electro-optical responses obtained for PDLC films based on photochemically crosslinked poly-2EHA (polycross-2EHA)/LC films exhibiting both a thickness of $19 \mu \mathrm{m}$. An important improvement of the electro-optical response of the film prepared with E7 (4) was observed with respect to that of the commercial LC E7. In particular, the E7 (4) based film required much lower voltages to achieve the transparent state. Note also that the hysteresis effect was lower, and a slightly higher transmittance $\mathrm{T}_{\mathrm{ON}}$ was found compared to the film containing E7.

A certain number of parameters can be applied to evaluate more in detail the electro-optical properties of PDLC films, such as the threshold voltage $\left(\mathrm{V}_{10}\right)$ [36]. $\mathrm{V}_{10}$ is defined as the electric voltage required to obtain a transmittance of $10 \%$ of the PDLC film, and was found to be determined by the balance between surface anchoring and electric forces [37]. As shown in Figure $7 \mathrm{~b}, \mathrm{~V}_{10}$ increases with increasing PDLC film thickness. Moreover, the films prepared with the modified LC present significantly lower $V_{10}$ values compared to those based on the pure LC E7. The presence of E7 (4) leads thus to a significant enhancement of the electrooptical properties.

\section{Conclusions}

The phase behavior of a poly-2EHA/E7 system was examined by two different techniques POM and DSC, exhibiting a strong increase of the nematic-isotropic transition temperature when increasing the poly-2EHA concentration, which can be explained by preferential miscibility effects and phase-separation phenomena involving the polymer, as well as the different LC constituents. The GC-MS analysis allowed to obtain qualitative and quantitative data of the LC content confined in phase separated domains, and revealed thus the change of LC composition within these regions, compared to pure E7. Interestingly, the electro-optical response obtained for PDLC films elaborated with a model LC blend, E7 (4), chosen as a 
result from substantial preferential miscibility phenomenon, shows a significant improvement of the electro-optical properties compared to the films prepared with pure E7.

\section{Acknowledgements}

This work has been accomplished in the framework of an international research program. The authors gratefully acknowledge the support of the Algerian Ministry of Higher Education and Scientific Research (MESRS), the University of Tlemcen/Algeria, the French Ministry of Higher Education and Research (MENESR), the CNRS, the University Lille 1 - Sciences and Technologies/France, and the CROUS of Lille/France.

\section{References}

[1] Doane W. Polymer dispersed liquid crystals, World Scientific, Singapore, 1990.

[2] Drzaic P. Liquid crystal dispersions, World Scientific, Singapore, 1995.

[3] Crawford GP, Zumer S. Liquid crystals in complex geometries, Taylors \& Francis, London, 1996.

[4] Jeon YJ, Bingzhu Y, Rhee JT, et al. Application and new developments in polymer dispersed liquid crystal simulation studies. Macromol Theory Simul. 2007;16(7):643-659. doi:10.1002/ mats.200700008.

[5] Javadian S, Dalir N, Gilani A, et al. A new approach to study interaction parameters in cyanobiphenyl liquid crystal binary systems. J Chem Thermodyn. 2015;80:22-29. doi:10.1016/j.cap.2012.03.019.

[6] Pauluth D, Tarumi K. Advanced liquid crystals for television. J Mater Chem. 2004;14(8):1219-1227. doi: 10.1039/B400135B. 
[7] Silva M, Figueirinhas JL, Sotomayor JC. Improvement of permanent memory effect in PDLC films using TX-100 as an additive. Liq Cryst. 2016;43(1):124-130. doi: 10.1080/02678292.2015.1061713.

[8] Marinov YG, Hadjichristov GB, Petrov AG, et al. Electro-optical response of polymerdispersed liquid crystal single layers of large nematic droplets oriented by rubbed teflon nanolayers. J Appl Phys. 2013;113(6):064301. doi: 10.1063/1.4789897.

[9] Liu YJ, Ding X, Lin SC, et al. Surface acoustic wave driven light shutters using polymerdispersed liquid crystals. Adv. Mater. 2011;23(14):1656-1659. doi: 10.1002/adma.201003708.

[10] Lee JW, Kim JK, Ahmad F, et al. Properties of thiol-vinyl PDLC films without additional photoinitiator. Liq Cryst. 2014;41(8):1109-1115. doi:10.1080/02678292.2014.904013.

[11] Su YC, Chu CC, Chang WT, et al. Characterization of optically switchable holographic polymer-dispersed liquid crystal transmission gratings. Opt Mater. 2011;34(1):251-255. doi:10.1016/j.optmat.2011.08.022.

[12] Lai YT, Kuo JC, Yang YJ. A novel gas sensor using polymer-dispersed liquid crystal doped with carbon nanotubes. Sens Actuators Phys. 2014;215:83-88. doi:10.1016/j.sna.2013.12.021.

[13] Xiong GR, Han GZ, Sun C, et al. Phototunable microlens array based on polymer dispersed liquid crystals. Adv Funct Mater. 2009;19(7):1082-1086. doi:10.1002/adfm.200801335.

[14] Bezrodna T, Melnyk V, Vorobjev V, et al. Low-temperature photoluminescence of 5CB liquid crystal. J Lumin. 2010;130(7):1134-1141. doi:10.1016/j.jlumin.2010.02.009. 
[15] Perju E, Marin L, Grigoras VC, et al. Thermotropic and optical behaviour of new PDLC systems based on a polysulfone matrix and a cyanoazomethine liquid crystal. Liq Cryst. 2011;38(7):893-905. doi: 10.1080/02678 292.2011.585250.

[16] Li MS, Fuh AY, Huang YH, et al. Electrically switchable high-fold-helix spiral phase plate based on polymer dispersed liquid crystals. Appl Phys Express. 2013;6(11):112201. doi:10.7567/APEX.6.112201.

[17] Lin YH, Chu TY, Tsou YS, et al. An electrically switchable surface free energy on a liquid crystal and polymer composite film. Appl Phys Lett. 2012;101(23):233502. doi:10.1063/1.4769093.

[18] Hsu TC, Lu CH, Huang YT, et al. Concentric polymer-dispersed liquid crystal rings for light intensity modulation. Sens Actuators Phys. 2011;2(169):341-346. doi:10.1016/j.sna.2011.01.018.

[19] Mucha M. Polymer as an important component of blends and composites with liquid crystals. Prog Polym Sci. 2003;28(5):837-873. doi:10.1016/S0079-6700(02)00117-X.

[20] Bronnikov S, Kostromin S, Zuev V. Polymer-dispersed liquid crystals: progress in preparation, investigation, and application. J Macromol Sci Part B. 2013;52(12):1718-1735. doi:10.1080/00222348.2013. 808926.

[21] Perju E, Paslaru E, Marin L. Polymer-dispersed liquid crystal composites for bioapplications: thermotropic, surface and optical properties. Liq Cryst. 2015;42(3):370-382. doi: $10.1080 / 02678292.2014 .992055$.

[22] Nolan P, Tillin M, Coates D. Liquid crystal microdroplet composition in a UV cured PDLC film. Mol Cryst Liq Cryst. Lett. 1992;8(6):129-135.

[23] Nwabunma D, Kyu T. Phase behavior, photopolymerization, and morphology development in mixtures of eutectic nematic liquid crystal and photocurable monomer. Polymer. 2001;42(2):801-806. doi:10.1016/S0032-3861(00)00368-2. 
[24] Deshmukh RR, Malik MK. Effect of temperature on the optical and electro-optical properties of poly(methylmethacrylate)/E7 polymer-dispersed liquid crystal composites. J Appl Polym Sci. 2008;109(1):627-637. doi:10. 1002/app.27933.

[25] Gogibus N, Benmouna F, Bernd E, et al. Phase diagrams of poly(siloxane)/liquid crystal blends. J Polym Sci Part B Polym Phys. 2003;41(1):39-43. doi: 10.1002/polb.10348.

[26] Bedjaoui L, Gogibus N, Ewen B, et al. Preferential solvation of the eutectic mixture of liquid crystals E7 in a polysiloxane. Polymer. 2004;45(19):6555-6560. doi:10.1016/j.polymer.2004.07.050.

[27] Bouchaour T, Benmouna F, Leclercq L, et al. Phase equilibrium of poly(n-butyl acrylate) and E7. Liq Cryst. 2000;27(3):413-420. doi:10.1080/026782900202877.

[28] Bedjaoui L, Bensaid H, Gordin C, et al. Solubility effects of multicomponent liquid crystal blends towards poly(n-butyl-acrylate). Liq. Cryst. 2011;38(10):1315-1320. doi:10.1080/02678292.2011.311261.

[29] Ellahi M, Gao Y, Yang H. Effects of di and tetra functional epoxy monomers structure on the morphology and the electro-optical properties of polymer-dispersed liquid crystal films. Int J Sci Tech Res. 2013;2(3):127-130.

[30] Ellahi M, Liua F, Song P, et al. Characterization and morphology of polymer-dispersed liquid crystal films. Soft Mater. 2014;12(3):339-345. doi:10.1080/1539445X.2013.807824.

[31] Brás ARE, Casimiro T, Aguiar A, et al. Characterization of a nematic mixture by reversed-phase HPLC and UV spectroscopy: an application to phase behaviour studies in liquid crystal- $\mathrm{CO}_{2} \quad$ systems. Liq $\quad$ Cryst. 2007;34(5):591-597. doi:10.1080/02678290601010915.

[32] Li J, Wen $\mathrm{CH}$, Gauza S, et al. Refractive indices of liquid crystals for display applications. J Disp Technol. 2005;1(1):51-61. 
[33] Kara-Slimane S, Benmouna F, Benmouna M, et al. Thermophysical behaviour of monofunctional acrylate and liquid crystal systems. Eur Polym J. 2002;38(3):461-466. doi:10.1016/S0014-3057(01)00202-6.

[34] Kara-Slimane S, Maschke U, Benmouna F, et al. Phase properties of poly(2ethylhexylacrylate)/E7 systems. Mol Cryst Liq Cryst. 2004;412(1):485-491. doi : $10.1080 / 15421400490432092$.

[35] Bedjaoui L, Benmouna M, Bouchaour T, et al. Selective solubility of E7 components in poly(n-butylacrylate). Mol Cryst Liq Cryst. 2004;411(1):537-544. doi:10.1080/15421400490436458.

[36] Kim Y, Jung D, Jeong S, et al. Optical properties and optimized conditions for polymer dispersed liquid crystal containing UV curable polymer and nematic liquid crystal. Curr Appl Phys. 2015;15(3):292-297. doi:10.1016/j.cap.2014.12.027.

[37] Ellahi M, Rafique MY, Gao Y, et al. Study on the effects of isotropic cross-linked pristine morphology and electro-optical properties of PDLC films. Polym Bull. 2015;72(11):2917-2930. doi:10.1007/s00289-015-1444-y. 